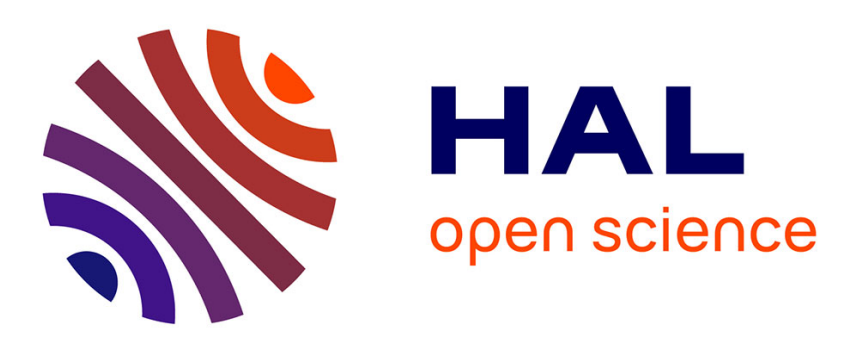

\title{
Right or left? Determining the hand holding the tool from use traces
}

\author{
Alice Rodriguez, Emmanuelle Pouydebat, M. Gema Chacón, Marie-Hélène \\ Moncel, Raphael Cornette, Ameline Bardo, Laurence Chèze, Radu Iovita, \\ Antony Borel
}

\section{To cite this version:}

Alice Rodriguez, Emmanuelle Pouydebat, M. Gema Chacón, Marie-Hélène Moncel, Raphael Cornette, et al.. Right or left? Determining the hand holding the tool from use traces. Journal of Archaeological Science: Reports, 2020, 31, 27p. 10.1016/j.jasrep.2020.102316 . hal-02615493

\section{HAL Id: hal-02615493 https://hal.science/hal-02615493}

Submitted on 27 May 2020

HAL is a multi-disciplinary open access archive for the deposit and dissemination of scientific research documents, whether they are published or not. The documents may come from teaching and research institutions in France or abroad, or from public or private research centers.
L'archive ouverte pluridisciplinaire HAL, est destinée au dépôt et à la diffusion de documents scientifiques de niveau recherche, publiés ou non, émanant des établissements d'enseignement et de recherche français ou étrangers, des laboratoires publics ou privés. 
Alice Rodriguez ${ }^{\text {ah }}$, Emmanuelle Pouydebat ${ }^{b}, M$. Gema Chacón ${ }^{\text {cda }}$, Marie-Hélène Moncel ${ }^{\mathrm{a}}$, Raphaël Cornette $^{\mathrm{e}}$, Ameline Bardo ${ }^{\dagger}$, Laurence Chèze ${ }^{g}$, Radu lovita ${ }^{\text {hi }}$, Antony Borel ${ }^{\mathrm{aj}}$

a) Histoire Naturelle de l'Homme Préhistorique (HNHP), Muséum national d'histoire naturelle, CNRS, UPVD, 1 Rue René Panhard, 75013 Paris, France.

b) Mécanismes adaptatifs et évolution (MECADEV), Muséum national d'Histoire naturelle, CNRS, 57 rue Cuvier, CP 55, 75005 Paris, France.

c) Institut Català de Paleoecologia Humana i Evolució Social (IPHES), Zona Educacional 4, Campus Sescelades URV (Edifici W3), 43007 Tarragona, Spain.

d) Universitat Rovira i Virgili (URV), Àrea de Prehistòria, Avinguda Catalunya 35, 43002, Tarragona, Spain.

e) Institut de Systématique, Évolution, Biodiversité (ISYEB), Muséum national d'Histoire naturelle, CNRS, Sorbonne Université, EPHE, Université des Antilles, 57 rue Cuvier, CP 50, 75005 Paris, France.

f) Skeletal Biology Research Centre, School of Anthropology and Conservation, University of Kent, Marlowe Building, Canterbury, CT2 7NR, United Kingdom.

g) Univ. Lyon, Université Claude Bernard Lyon 1, IFSTTAR, LBMC UMR_T9406, F69622, Lyon, France.

h) Anthrotopography Laboratory, Center for the Study of Human Origins, Department of Anthropology, New York University, New York City, USA.

i) Early Prehistory and Quaternary Ecology, University of Tübingen, Tübingen, Germany.

j) Institute of Archaeological Sciences, Eötvös Loránd University, Múzeum krt. 4/b, 1088 Budapest, Hungary.

Abstract:

Currently, approximately $90 \%$ of the human population is right-handed. This handedness is due to the lateralization of the cerebral hemispheres and is controlled by brain areas involved in complex motor tasks such as making stone tools or in language. In addition to describing the evolution of laterality in humans, identifying hand preference in fossil hominids can improve our understanding of the emergence and development of complex cognitive faculties during evolution. Several fields of prehistory like palaeoanthropology or lithic analysis have already investigated handedness in fossils hominins but they face limitations due to either the incomplete or the composite state of the skeleton remains or to results replication or method application failure. Wear analysis could provide new complementary data about hand preference evolution and the development of certain complex 
cognitive functions using indirect evidence (use traces, micro-scars in particular) of the hand holding the stone tool during use. Controlled experiment has been carried out in order to establish a reference collection of tools used with the left and tools used with the right hand. Wear analysis was performed on this corpus using "classical" microscopic approach and geometric morphometric analysis. A machine learning algorithm, the k-NN method, was applied to verify if use traces (micro-scars) could help determine the hand holding the tool during use. The best model, based on parameters referring to invasiveness of micro-scars, was able to correctly determine the hand holding the tool with $75 \%$ accuracy.

\section{Introduction:}

Hand preference is defined by the hand with which an individual performs a specific task (e.g. Annett, 1985; Uomini and Gowlett, 2013). Several studies have demonstrated that hand preference is linked to the lateralization of the cerebral hemispheres and is related to areas of the brain similar to those involved in the control of other essential functions such as language (e.g. Corballis, 2003; Meguerditchian et al., 2013; Stout et al., 2000; Uomini and Meyer, 2013; Willems and Hagoort, 2007). Thus, in addition to describing the evolution of laterality in humans, identifying hand preference in fossil hominids can improve our understanding of the emergence and development of complex cognitive faculties during evolution (e.g. Steele and Uomini, 2009; Stout et al., 2008).

Currently, between $74 \%$ and $96 \%$ of the human population preferentially uses the right hand (Annett, 1985; Llaurens et al., 2009; Porac and Coren, 1981). Lefthanders are a minority in all human populations. The highest rate of left-handers recorded in a population is found among the Eipo in Papua New Guinea and is estimated at 26.9\% (Faurie et al., 2005).

The control of fine manual actions (called "complex" motor actions) is attributed to the left hemisphere which would explain the preferential use of the right hand for this type of action (e.g. Greenfield, 1991; Johnson-Frey et al., 2005; Lewis, 2006; Schluter et al., 2001). Some authors have thus hypothesized the development of a strong manual preference in relation to the manufacture and complexity of tools (Corballis, 1987; Stock et al., 2013; Uomini and Gowlett, 2013; Uomini, 2009). Other studies show a greater effect of the nature and demands of the task as well as the type of object involved and the speed of the action (Forrester et al., 2013, 2012, 2011; Pouydebat et al., 2014; Quaresmini et al., 2014; Rogers, 2009). The complexity of the task is therefore probably not the only criterion explaining the emergence of a strong manual preference. Establishing a direct link between strong manual preference and the complexity of (stone) tools is difficult and, so far, concrete archaeological data do not support it. Moreover, few studies highlight 
the fact that the right hemisphere is also involved and essential in activities such as tool use (Frey and Gerry, 2006; Hartmann et al., 2005; Stout and Chaminade, 2012)

In non-human primates, especially great apes, similarly strong lateralization as in humans is missing (Vallortigara and Rogers, 2005). This differs according to the species but also within the same species at an individual level or a population level (Cashmore et al., 2008; Chapelain et al., 2011; Hopkins, 2006; Marzke, 2013; McManus, 2009). Differences in hand preference among nonhuman primates appear to be due to complex relationships between various factors, such as the environment (life in the wild or captivity), or the complexity and nature of the task (type, speed) (e.g. Fagot and Vauclair, 1991; Hopkins et al., 2011; McGrew and Marchant, 1997; Mosquera et al., 2012; Pouydebat et al., 2014).

The origin of this peculiarity during human evolution is for the moment unknown. So far, data about fossil hominin hand preference are mainly coming from the skeleton, either directly inferred from forelimb asymmetries or indirectly from the skull. The examination of bone asymmetries on the upper limbs of fossil hominids could deliver direct indications of hand preference. However, as suggested or stated in several studies, observed differences in hand entheses (the surfaces where ligaments are attached on bones) among individuals with the same occupation could be due to numerous variables including inter-individual genetic variability, nutrition or hormone levels, and not just manual activities (Foster et al., 2014; Karakostis et al., 2018, 2017; Karakostis and Lorenzo, 2016).

On the other hand, other measurements of upper limb asymmetries have been used to identify human hand preference (Shaw, 2011; Trinkaus et al., 1994). Based on such observation, Sparacello et al. (2017) studied a sample of humeri coming from 107 Late Pleistocene individuals and obtained a distribution of hand preference similar to the distribution obtained with recent human samples (i.e. right: $74.8 \%$, left: $15.0 \%$, ambiguous: $10.3 \%$ ). Others suggested for example that the articular constraints model could help in the identification of hand preference (Lazenby et al., 2008) or that the analysis of trabecular bone could contribute to the identification of right/left directional asymmetry (Stephens et al., 2016).

Moving on to the skull, analyses of cranial endocast asymmetries analyses (e.g. Balzeau et al., 2012; Holloway, 1981; Holloway and De La Costelareymondie, 1982; Poza-Rey et al., 2017) suggested possible relationships between hand preference, endocranial shape, and functional capacities in hominins. Other studies, investigating striations on teeth surfaces, show that even for the Middle Palaeolithic and species such as Homo erectus in Asia, or Homo heidelbergensis and Homo neanderthalensis in Europe, the right hand was already the chosen hand for the majority of individuals, both adults or young individuals (e.g. Bermúdez de Castro et al., 2003, 1988; Condemi et al., 2017; Estalrrich and Rosas, 2013; Fiore et al., 2015; Frayer et al., 2012, 2010; Lozano et al., 2009; Poza-Rey et al., 2017; Xing et al., 2017). This could be the case as early as $1.8 \mathrm{Ma}$ as suggested by the study of labial striations on the $\mathrm{OH}-65$ fossil's anterior teeth (Lozano et al., 2017). 
For younger periods, analysis of wall-paintings and striations on bone tools may give clues about the hand preference of their authors or users respectively (see Spenneman, 1984 for an example concerning Neolithic).

These studies do not provide data supporting a ratio of left- and right-handers clearly different from now in Prehistory (see Llaurens et al., 2009). However, the more we go back in time the more the application of these methods to extinct hominin species have serious limitations. Relatively bad conservation of skeletal remains often prevents any analysis of traces that are relevant for determining hand preference. Also, apart from the limited number of individuals which could be studied (see table 2.1 of Faurie et al., 2016 for a summary of fossil hominin data for laterality and corresponding references) palaeoanthropology faces the problem of the partial skeleton remains which implies sometimes to study composite anatomical elements composed of bones coming from different individuals (see Cashmore, 2009).

On the contrary, stone tools are often abundant in Palaeolithic sites. The data they could provide regarding hand preference are therefore likely to be statistically more representative if whole sets of assemblages are analysed. Different studies have intended to set up a methodology to determine hand preference based on the observation of manufacture features appearing on stone tools (size and shape of flake scatter patterns: Newcomer and Sieveking, 1980; dorsal cortex position: Toth, 1985; occurrence of cortex and relic margins: Bradley and Sampson, 1986; orientation of the cone of percussion: Rugg and Mullane, 2001; resharpening techniques: Cornford, 1986; combination of technical features: Bargalló et al., 2018, 2017; Bargalló and Mosquera, 2014). These methods give variable results and a recent work from Ruck et al. (2015), applying Toth's, Rugg and Mullane's and Bargalló and Mosquera's methods, showed that these methods were not able to determine the hand holding the hammer for the studied flakes production better than a random guess (see also Patterson and Sollberger, 1986; Pobiner, 1999; Uomini, 2011, 2001).

The identification of the knapper hand preference based on the spatial organization of debitage remains have also been investigated giving successful results in experimental conditions but the authors highlight the difficulties in applying such method in an archaeological context (Bargalló et al., 2018).

Some of these methods should be investigated further in order to improve their rate of correct determination and their applicability to archaeological samples. However, producing a stone flake is a quick and punctual activity. Therefore, any variation during this short production moment might modify the types of features appearing on the flake. The poor rates of success in identifying hand preference from patterns in flake production may be due to the high variability of factors influencing the production of any particular flake. On the other hand, a repeated activity or movement is likely to leave behind a stronger "signature" of the hand preference. Therefore, 
focusing on stone tool use rather than stone tool production could provide better results in identifying hominids hand preference. A handful of studies have attempted to extract hand preference from stone tool use (based on asymmetries of the tool: Brinton, 1896; based on direction of rotation of boring artefacts: Cahen et al., 1979; Cahen and Keeley, 1980; Keeley, 1977; see also Uomini, 2008). Others simply discuss why it is difficult to do so (D'Errico, 1992; Semenov, 1970; Weber, 1990). However, to our knowledge, most of them only briefly mention this question and none is based on an experimental reference collection that was statistically tested to allow the identification of specific criteria corresponding to the use of the tool in the right or left hand.

Here, we propose to examine if hand preference can be identified from use-wear on stone tools through qualitative (traditional wear observation) and quantitative (measurements and geometric morphometric) wear descriptors. A machine learning algorithm is used for the first time on these data in order to test which of the descriptors is/are the most relevant to recognize the hand holding the tool based on the traces of use.

\section{Materials and methods}

\subsection{Experimental setup}

Tools:

Numerous variables (morphology and raw material type of the tool, worked material, working angle, direction of movement, etc.) can have an effect on the formation of traces on the surface of a stone tool. In order to characterise traces of use related to hand preference but also quantify their variability, it is first essential to limit the effect of these variables and particularly the effect of the form of the tool. Therefore, the form of the tool was standardized using soda-lime glass replicas of a Levallois point (lovita et al., 2014; figure 1). The use of this glass has the advantage to simulate the type of conchoidal fracture of many raw materials used in prehistory. These artefacts measured $64.5 \mathrm{~mm}$ long, $36.5 \mathrm{~mm}$ at the maximal width and $6 \mathrm{~mm}$ at the maximal thickness, with a weight of $15.8 \mathrm{~g}$ on average.

\section{Figure 1 (1 column)}

Users:

A total of 20 volunteers participated in the experiment, 10 right-handed subjects ( 5 women and 5 men) and 10 left-handed subjects ( 5 women and 5 men). They were beginners in using stone tools; none of them had used prehistoric tools before. The subjects were not aware of the fact that the aim of the experiment was related to hand preference in order to limit modification of their behaviour. Their hand preference was documented along with a number of other variables, including name, age, sex, size, weight, hand size, circumference of the last phalanx of each finger 
of the hand holding the tool, palm length, palm width, expertise, previous injuries in order to prevent them from identifying the aim of the study.

\section{Worked material:}

Wooden (Pinus) sticks with no bark were provided to each subject. These sticks were of standardized diameter $(18 \mathrm{~mm})$ and length $(50 \mathrm{~cm})$.

\section{Task:}

Each individual had to sit on a chair and to saw wooden sticks with three different tools. Each tool was used for a total duration of 20 minutes. The number of strokes was not constrained but number of strokes (forward + backward $=1$ ) per minute was measured during the $5^{\text {th }}, 10^{\text {th }}$ and $15^{\text {th }}$ minutes in order to approximate the speed of the sawing movement (in $\mathrm{mvt} / \mathrm{min}$.) (Whole experiment: $\min =98.33 \mathrm{mvt} / \mathrm{min} ., \max =191.33 \mathrm{mvt} / \mathrm{min}$. , mean $=135.96 \mathrm{mvt} / \mathrm{min} ., \mathrm{SD}=23.59$ $\mathrm{mvt} / \mathrm{min}$.; for left hand users: $\min =98.33 \mathrm{mvt} / \mathrm{min} ., \max =191.33 \mathrm{mvt} / \mathrm{min}$., mean $=141.74$ $\mathrm{mvt} / \mathrm{min}$., $\mathrm{SD}=25.37 \mathrm{mvt} / \mathrm{min}$.; for right hand users: $\min =100.3 \mathrm{mvt} / \mathrm{min}$., $\max =166 \mathrm{mvt} / \mathrm{min}$., mean = $129.9 \mathrm{mvt} / \mathrm{min}$., SD = $20.41 \mathrm{mvt} / \mathrm{min}$; ; see the dataset in supplementary material). Before the experiment proper, a five-minute test was carried out without any instructions to observe how individuals hold and use the tool spontaneously, and to evaluate the constrains of our controlled experiment on the tool grasping mode. The first tool of the proper experiment was used with the only instruction to use the predefined edge. For the second and third tools, the participants had to use the predefined edge and keep the wooden stick horizontal on their knees. Each experiment was recorded individually and documented by one observer using a Samsung NV24HD video camera.

\subsection{Analysis \\ Description of micro-scars}

Each stone tool was observed with a stereomicroscope (Zeiss Discovery V8 with Plan S $1.0 x$ objective; FWD $=81 \mathrm{~mm}$; it is equipped with a ToupTek camera with a resolution of 5 MPixels) before use at $10 x$ (objective $F O V=23 \mathrm{~mm}$ ) and $80 x$ (objective FOV $=2.9 \mathrm{~mm}$ ) magnifications. Then, the tools were cleaned (in a solution of DERQUIM LM02 phosphate free neutral soap at $5 \%$ in ultrasonic-bath during $15 \mathrm{~min}$ ), and moulded (using Heraeus PROVIL®novo Light Regular silicone) and casted (using Axson F180 polyurethane resin) to keep a record of their original morphology before use. The tools were then used for a total duration of 20 minutes each. After use, they were cleaned again (same procedure as before use) and observed at 10x and 80x magnifications (with the Zeiss Discovery V8).

Micro-scars were documented before and after use on both sides of the tool. Their amount, position (ventral or dorsal face), type, orientation, and (position of) maximum extent on the surface perpendicularly to the edge were recorded (Figure 2). The type of micro-fractures was described 
following the typology of the Ho Ho Committee (1979): fracture, feathered and step. We added the type "abrupt" to refer to scars which were not straight as a fracture but too steep to enter in the category "feathered". Three categories were used for the orientation of the scars: perpendicular to the edge, oriented distally (towards the point) and proximally (towards the butt).

Statistical tests were performed in $R$ (R Core Team, 2019). As the assumptions of normality and equality of variance for t-test were not met, we used non-parametric Mann-Whitney $U$ tests to verify if the number of micro-scars and if their invasiveness were different depending on the hand holding the tool during use. The Cochran's rule being respected, we used chi-square test to examine if the type of micro-scars, their orientation and the face where they appeared were independent of the user, of the user's sex and of the hand holding the tool during use.

\section{Figure 2 (1 column)}

\section{Edge modification visualization and quantification}

Photograph of each tool was taken before and after use. The same camera was not available during the whole study. Pictures were taken with a Nikon D300 equipped with a Tamron 16-300mm F/3.5-6.3 Di II VC PZD objective before use (pictures were taken at a focal length of $200 \mathrm{~mm}$ ) and with a NIKON 7100 with an AF-D Micro NIKKOR 60mm 1:2.8G ED objective after use.

As they were taken with different conditions, the two batches of photos (i.e. from before and after use) were first scaled. They were then binarized with Adobe Photoshop. The Momocs (Bonhomme et al., 2014) and geomorph (Adams et al., 2019) libraries for $\mathrm{R}$ were used for the analysis of the shape of the tool edges. The outlines of the tools were automatically extracted from the binarized images. The outlines were then aligned and cut to keep only the area of interest displaying the modifications due to use: the used edge of each tool (Figure 3). The remaining curves corresponding to the used edges of each tool were defined by two landmarks, one at each extremity, and by 1000 equidistant "sliding-semilandmarks" distributed between these two points. A high number of points was chosen because the sought shape differences are due to the microscaring of the edges and can be very fine. The space between each "semilandmark" was then optimized by allowing them to slip between the previous and the next point in order to minimize the Procruste distance with the pseudo-homologous point of the Procrustes mean shape (see Gunz and Mitteroecker, 2013). This optimization aims to limit the effect of the former arbitrary spacing of the points (Gunz and Mitteroecker, 2013; Perez et al., 2006), here equidistant. This optimization and the superposition of the curves were carried out by Generalized Procrustean Analysis (GPA). The new coordinates obtained by GPA were used to calculate a Principal Component Analysis (PCA) and to visualize, with transformation grids (Klingenberg, 2013), the axes on which the shape variations were the most important according to the manual preference. A Procrustes multivariate analysis of variance (Procrustes ANOVA using the function "procD.Im" of package geomorph in R) 
was used to test if the shape differences visualized according to the recorded factors (e.g. hand holding the tool during use) were statistically significant. In other words, it allowed us to check if specific scar distributions and specific used edge morphologies can be linked to the hand holding the tool during use (i.e. left or right hand). The relationship between individuals' sex and the resulting used edge shape was also tested.

\section{Figure 3 ( 2 columns)}

\section{k-Nearest Neighbours model}

In order to verify if the qualitative and quantitative descriptors of scars could be used to discriminate a tool used with the right hand from a tool used with the left hand, we used the $k$ Nearest Neighbours (k-NN) machine learning algorithm. It was computed using the "caret" library (Kuhn et al., 2019) in R. This algorithm uses Euclidean distances to find the k-Nearest Neighbours of the artefact to be classified. The class which is the most frequent among the $k$ Nearest Neighbours is given to the unknown artefact (see Domínguez-Rodrigo and Baquedano, 2018 for an example of application on cut-marks on bones). Twenty-one combinations of different descriptors were tested:

1) Number of scars on the ventral and dorsal faces of the tool

2) types of scars on both faces

3) types of scars on dorsal face

4) types of scars on ventral face

5) directions of scars on both faces

6) directions of scars on dorsal face

7) directions of scars on ventral face

8) types and directions of scars on both faces

9) number, types and directions of scars on both faces

10) the 59 first principal components of the PCA on geometric morphometric data

11 ) the 2 first principal components of the PCA on geometric morphometric data

12) the 59 first principal components of the PCA on geometric morphometric data and the number of scars on both faces

13) position of the scar with the maximum extent on the surface perpendicularly to the edge on ventral face

14) position of the scar with the maximum extent on the surface perpendicularly to the edge on dorsal face

15) position of the scar with the maximum extent on the surface perpendicularly to the edge on both faces

16) maximum scar extent on the surface perpendicularly to the edge on ventral face

17) maximum scar extent on the surface perpendicularly to the edge on dorsal face 
18) maximum scar extent on the surface perpendicularly to the edge on both faces

19) maximum scar extent and position of the scar with the maximum extent on the surface perpendicularly to the edge on both faces

20) all descriptors from microscopic observation

21) all descriptors from microscopic observation and geometric morphometrics

We normalized the descriptors so their values were comprised between 0 and 1 to avoid emphasizing descriptors with larger ranges of values. Each configuration was tested with each odd number between 3 and 59 as $\mathrm{k}$ value ( 3 being the minimum odd number for such model and 59 the maximum in our case as we had 60 artefacts). The $\mathrm{k}$ value of the final model was chosen based on the obtained accuracy and kappa for each model. As our sample size $(N=60)$ is quite small, we used leave-on-out cross-validation method to evaluate the models. In this method, the whole sample set of analysed artefacts but one is used as a training set and the removed artefact is used as a testing set. This procedure is repeated as many times as the number of artefacts in the sample set. In addition, we used kappa statistics (value between -1 and 1 which measures the agreement between observed and expected accuracy; negative values indicate disagreement, and the degree of agreement increase from $>0$ to 1), sensitivity (a measure of the proportion of attributed classes - i.e. positives - which are correctly attributed - i.e. true positives) and specificity (a measure of the proportion of rejected classes - i.e. negatives - which are correctly rejected - i.e. true negatives) to evaluate the performance of the selected model.

\section{Results}

\subsection{Scars description}

The scars qualitative description showed that independently of the hand holding the tool during use: 1) tools have more extended scars on their dorsal face than on the ventral face, 2) tools have mostly continuous scars on the dorsal face and discontinuous scars on the ventral face, 3) scars can be distributed all along the used edge and 4) scars are mostly perpendicular to the edge. Therefore, no significant difference of position, type and orientation of scars between tools used by left-handers and right-handers was noticed (Figure 4 and Supplementary figures 1 to 7 ).

However, right-handed subjects produced significantly more micro-scars than left-handed subjects $(\bar{X}=81.42, \mathrm{sd}=39.84$ for the tools used by right-handers versus $\bar{X}=53.04, \mathrm{sd}=18.60$ for the left-handers; Mann-Whitney $U$ one-tailed test: $W=240, p$-value $=0.0011$ ). Micro-scars were also significantly less invasive on tools used by left-handed subjects $(\bar{X}=2.45 \mathrm{~mm}, \mathrm{sd}=1.13 \mathrm{~mm}$ for the tools used by right-handers versus $\bar{X}=1.63 \mathrm{~mm}$, sd $=0.73 \mathrm{~mm}$ for the left-handers; MannWhitney $U$ one-tailed test: $W=771$, $p$-value $<0.0001$ ).

The hypothesis of independence between the hand holding the tool and the type of microscars appearing on the surface of the tool could be rejected $\left(X^{2}=43.371, \mathrm{df}=4, \mathrm{p}\right.$-value $<$ 0.0001 ). However, independence could not be rejected concerning the hand holding the tool and 
the orientation of micro-scars $\left(\mathrm{X}^{2}=0.66197, \mathrm{df}=2, \mathrm{p}\right.$-value $\left.=0.7182\right)$ and the face where microscars were located $\left(X^{2}=2.1323, d f=1, p\right.$-value $\left.=0.1442\right)$.

Among other chi-squared tests performed on this dataset we can notice that the type of micro-scars is not independent from the sex of the user $\left(X^{2}=89.084, \mathrm{df}=4, \mathrm{p}\right.$-value $\left.<0.0001\right)$ and that the type of micro-scars, the orientation and the face where appeared micro-scars are not independent from the user (respectively $X^{2}=587.75$, $\mathrm{df}=76, \mathrm{p}$-value $<0.0001 ; \mathrm{X}^{2}=240.43$, $\mathrm{df}=$ 38 , $p$-value $<0.0001$ and $X^{2}=114.05, d f=19$, $p$-value $\left.<0.0001\right)$.

\section{Figure 4 ( 2 columns) and Supplementary figures 1 to 7}

3.2. Edge modification visualization and quantification through geometric morphometric

3.2.1. Comparison of edges before and after use

Before computing the geometric morphometric analysis, the extraction of each edge of interest before and after use allowed comparing them to visualize the location of edge modifications and the amount of removed material during use (Figure 5 and Supplementary figures 8 to 18 . Most of the modification seem to be on the middle and the rear of the edge. Few tools ( $40 \%, N=24 / 60)$ present modifications on the front part of the edge but these modifications are generally not invasive. No difference or clear tendency is noticed between tools used with left versus the right hand regarding the amount of removed material and the location of modifications.

\section{Figure 5 (1 column) and Supplementary figures 8 to 18}

\subsubsection{Used edges shapes quantification}

The first two axes of the PCA on shape data account respectively for $23.26 \%$ and $11.79 \%$ of the total variance (Figure 6). Groups of tools held with the right hand almost fully overlap with the group of tools held with the left hand. Procrustes ANOVA confirmed that no pattern of shape of used edge can be specifically attributed to tools used with the right hand versus tools used with the left hand. (Procrustes ANOVA: $d f=1, S S=0.0002, M S=0.0002, R s q=0.0247, F=1.4708, Z=$ $1.4315, \mathrm{p}$-value $=0.101)$. On the contrary, we noticed that the user and the sex of the user may have a larger effect (than the hand holding the tool) on the shape of the used edges (Procrustes ANOVA on shapes and users: $\mathrm{df}=19, \mathrm{SS}=0.0038, \mathrm{MS}=0.0002, \mathrm{Rsq}=0.4301 ; \mathrm{F}=1.5889 ; \mathrm{Z}=$ 4.5104; $p$-value $=0.001$; Procrustes ANOVA on shapes and sex of users: $\mathrm{df}=1$, $\mathrm{SS}=0.0002, \mathrm{MS}$ $=0.0002, \mathrm{Rsq}=0.0324 ; \mathrm{F}=1.9407 ; \mathrm{Z}=2.3377 ; \mathrm{p}$-value $=0.029)$. 


\section{3. $\mathrm{k}$ Nearest Neighbours model}

Among the 21 tested models, only five gave an accuracy of at least $75 \%$, all are based on descriptors concerning the maximum scar extent on the surface (perpendicularly to the edge). The best model includes the maximum scar extent and the position of the scar with the maximum extent on the surface (perpendicularly to the edge) on both faces. With a $k$ value set up at 5 , this model provided an accuracy of $75 \%$ (95\% confidence interval: $62 \%, 85 \%$ ) with an acceptable kappa of 0.51 , a sensitivity of $85 \%$ and a specificity of $67 \%$ (Table 1 ).

\section{Table 1 ( 2 columns)}

\section{Discussion}

\subsection{Can hand preference be identified from micro-scars?}

We could not document any significant difference in position, type, and orientation of scars between tools used by left-handers and right-handers. The microscopic observation showed that tools have more extended scars on their dorsal face than on the ventral face regardless of which hand the user preferred. Knowing that tools were always held with the same orientation during the sawing action (with the dorsal face on the right) this result is counter intuitive. Indeed, during the sawing action we usually observe a tilt of the tool toward the right for right-handers and towards the left for left-handers usually resulting in more scars on the face placed on the left for right-handers and on the right for left-handers. This result shows that hand preference has no influence on the distribution of scars on either of the tool's faces. Combined with the fact that these tools had a centred cutting edge, this result may show that the edge morphology and surface structure may have an effect on the distribution of scars (when the glass casts were made, imperfections on the edges were removed by polishing the ventral side of the edge only; this might have affected the resilience of this face).

On the other hand, the type of micro-scars seems to be related to the hand holding the tool during use. This is also a counter-intuitive result. However, as the tool had to be held in the same orientation by left-handers and right-handers, the forces applied by left-handers, theoretically symmetrical to those applied by right-handers, are applied on the opposite surface of the tool. As mentioned above, the surface might have different resilience to contact during use and, as a consequence, different types of micro-scars might have been produced. This should be tested in future experiments. The suggestion that one of the surfaces (i.e. the dorsal face) of the tools might be weaker than the other is somewhat supported by the fact that irrespective of which hand was holding the tool, the dorsal face exhibited more scars.

Comparison of the edges before and after use did not show significant difference between the amount of removed material and the location of modifications on tools used by left-handers and right-handers. Right-handed subjects produced significantly more invasive and more numerous 
micro-scars than left-handers but this is very likely to be due to an individual factor as, apart from hand preference, the sex and the user seem to have a negligible effect on the characteristics of the micro-scars. This was confirmed by geometric morphometric analyses which show that the shape of the used edges depends more on the user and user's sex than on the hand preference.

Based on the data gathered through microscopic observation of scars and quantification of edge modification with geometric morphometric, the $\mathrm{k}$ Nearest Neighbours method highlighted the importance of the maximum scar extent (on the ventral face) and of the position of the more invasive scar in discriminating hand preference during stone tool use. The model integrating these variables gave $75 \%$ of good identification of the hand preference of the user.

\subsection{Importance of individual characteristics}

We decided not to choose experts at this step of the project because expertize in using stone flakes (here more exactly soda lime-glass) is a complicated notion. How can we define an expert user of stone flakes? Beginners are sometimes performing very well in such tasks. Like for nowadays tools, a beginner might be more likely to damage the tool quicker than an expert might but can we really consider someone as an expert stone flake user in the current world? Few have more experience than others do and finding enough experienced people to produce statistically acceptable data is not straightforward. In addition, experts may not have been the users of all the archaeological pieces; expertise is not an information that we have archaeologically and we intended to find parameters, which do not depend on the expertise to identify hand preference.

Thus, all of the individuals involved in this experiment were beginners in prehistoric tool use. This lack of skill may be one of the reason why several scar features seem to be more related to individual characteristics than to hand preference. The variability of grip and movements, even if somehow constrained, likely influence scars production which may follow a pattern linked to the way each individual used the tool. It can be supposed that in prehistory, frequent use of stones as tools implies a certain degree of know-how and the transmission of this knowledge among members of a particular community. A certain regularity in the way stone tools were used might be expected. If so, individual characteristics might not exert such influence on scars features in archaeological assemblages. However, in any discipline, experts often develop idiosyncratic techniques which can be used to identify them. If stone tool use follows such a model, individual characteristics may be very important in the process of scars formation and, for a specific previously identified task, (even if unlikely because of the numerous variables possibly affecting tool surfaces) it might be possible to evaluate the minimum number of different users within an assemblage. This has to be tested in the future, involving experimenters skilled in stone tool use.

\subsection{Hand holding the tool versus hand preference}


The hand preference of an individual may vary depending on the action carried out (Provins, 1997). For instance, in the frame of this experiment, one individual declared himself as left-handed but spontaneously used the right hand to saw the wood during the whole experiment. Also, some of the individuals asked to change the hand holding the tool (which was not allowed here) because of pain due to this unusual task. In an unconstrained context (as in Prehistory), it is likely that individuals would change hand if they feel pain or discomfort. Such modification of the hand used during the tasks would highly complicate the identification of left-handed and righthanded people based on archaeological stone tools. However, we can think that, during Prehistory, stone tool use was a more frequent activity and pain and discomfort may have been less common. In any case, such behaviours (as well as the case of ambidextrous people) demonstrate that what we might intent to determine in an archaeological context is the hand holding the tool rather than the hand preference of the user. Only the study of large samples through multi-proxy examination might allow approaching hand preference.

\subsection{Archaeological application}

The results of this experiment, the k-NN results in particular, are promising and show that it might be possible to identify the hand holding the tool during use based on micro-scars extent and location. However, even if $75 \%$ of correct identification is acceptable, it remains valid for a constrained experimental context in wood sawing activity only. We can expect a drastic drop of accuracy in unconstrained situations. Indeed, it is for instance essential to consider that one tool could have been used several times, for various activities, and by different users. Furthermore, in an archaeological assemblage, it is very unlikely to deal only with artefacts used in sawing wood activities. It is now essential to extend the experimental reference corpus with unstandardized pieces (used for different activities), to improve the model with other traces (residues, micropolishes, striations), and to validate the results with blind-tests before any application on archaeological assemblages. Such an application could be considered when a strong enough (i.e. more than $90 \%$ accuracy) experimental model will be ready. It requires a large experimental collection on which each of the traces will be examined and documented. Our model involves parameters that are not dependent on the population ratio of right and lefthanders and is only based on repeatable measurements and description. Once improved, we will be able to propose a new proxy which could provide different result concerning hand preference ratio in Prehistory or reinforce the obtained results from the other disciplines.

\section{Conclusion}

Wear analysis, geometric morphometric and machine learning provided complementary results in order to examine if the hand holding the tool during use could be identified based on micro-scars. However, the k-NN method showed that the data provided by geometric morphometric and numerous data coming from wear analysis do not help in improving the 
accuracy of the model of classification. Nevertheless, counter-intuitive results may indicate a bias related to the structure of the tool used in this experiment and these non-significant variables from geometric morphometric and wear analysis should not be rejected definitively before further experiments. Moreover, the heterogeneity of raw materials used in prehistoric times may lead to similar results. The best model (75\% accuracy) is obtained when based on the maximum scar extent and the position of the scar with the maximum extent on the surface of the tool perpendicularly to the edge on both faces. Other variables show overlap for tools used with the left hand and tools used with the right hand, and are likely to depend rather on individual characteristics.

This first experiment, with standardized tools dedicated to hand preference identification, yielded promising results and already highlighted variables that could be used as discriminants. Nevertheless, the experimental corpus needs to be extended and the model tested further to provide reliable results from archaeological assemblages.

\section{Acknowledgments}

We thank Simon Puaud and Florent Détroit for their help and advices during the preparation of the experiments and Myriam Méziou, Anne-Cécile Haussonne and Anthony Herrel for logistic and funding administration. We are grateful to all the volunteers who participated.

Data acquisition and analysis were partly done thanks to the 2D/3D imaging and the Material characterisation platforms of the MNHN. The surface scanning laboratory of the IPHES also provided assistance for data acquisition.

Part of A. Rodriguez research was possible thanks to a grant to the Museum National d'Histoire Naturelle of Paris financed by the project "Robes de pierre", part of the POLYRE ('L'Aventure Polychrome') Chair of Excellence, supported by Sorbonne Universités. The PreMHo project is supported by funding from the French National Research Agency through LabEx ANR10-LABX-0003-BCDiv, in the program "Investissements d'avenir" ANR-11-IDEX-0004-02.

M.G. Chacón. research is funded by CERCA Programme/Generalitat de Catalunya, by Spanish Ministry of Science, Innovation and Universities (MICINN) of the Spanish Government, project no HAR2016-76760-C3-1-P and the Catalonian Government, research group's n 2017 SGR 836.

A. Bardo research was funded by the Fyssen foundation.

We are grateful to the two anonymous reviewers and editors who provided constructive comments, which contributed to improve this manuscript.

\section{References}

Adams, D.C., Collyer, M.L., Kaliontzopoulou, A., 2019. Geomorph: Software for geometric morphometric analyses. $\mathrm{R}$ package version 3.1.0.

Annett, M., 1985. Left, right, hand and brain: the right shift theory. Erlbaum, London. 
Balzeau, A., Gilissen, E., Grimaud-Hervé, D., 2012. Shared Pattern of Endocranial Shape Asymmetries among Great Apes, Anatomically Modern Humans, and Fossil Hominins. PLoS ONE 7, e29581. https://doi.org/10/fzdr7w

Bargalló, A., Mosquera, M., 2014. Can hand laterality be identified through lithic technology? Laterality: Asymmetries of Body, Brain and Cognition 19, 37-63. https://doi.org/10/gfvtk9

Bargalló, A., Mosquera, M., Lorenzo, C., 2018. Identifying handedness at knapping; an analysis of the scatter pattern of lithic remains. Archaeological and Anthropological Sciences 10, 587-598. https://doi.org/10/gfvwd9

Bargalló, A., Mosquera, M., Lozano, S., 2017. In pursuit of our ancestors' hand laterality. Journal of Human Evolution 111, 18-32. https://doi.org/10.1016/j.jhevol.2017.06.001

Bermúdez de Castro, J.M., Bromage, T.G., Jalvo, Y.F., 1988. Buccal striations on fossil human anterior teeth: evidence of handedness in the middle and early Upper Pleistocene. Journal of Human Evolution 17, 403-412. https://doi.org/10/c6mx2j

Bermúdez de Castro, J.M., Martinon-Torres, M., Sarmiento, S., Lozano, M., Arsuaga, J.L., Carbonell, E., 2003. Rates of anterior tooth wear in Middle Pleistocene hominins from Sima de los Huesos (Sierra de Atapuerca, Spain). Proceedings of the National Academy of Sciences 100, 11992-11996. https://doi.org/10.1073/pnas.2034879100

Bonhomme, V., Picq, S., Gaucherel, C., Claude, J., 2014. Momocs: Outline Analysis Using R. Journal of Statistical Software 56, 1-24. https://doi.org/10.18637/jss.v056.i13

Bradley, B., Sampson, C.G., 1986. Analysis of replication of two Acheulian artefact assemblages (Chiltern Hills), in: Stone Age Prehistory: Studies in Memory of Charles McBurney. G.N. Bailey and P. Callow, Cambridge, UK, pp. 29-45.

Brinton, D.G., 1896. Left-Handedness in North American Aboriginal Art. American Anthropologist 9, 175181.

Cahen, D., Keeley, L.H., 1980. Not less than two, not more than three. World Archaeology 12, 166-180. https://doi.org/10/fwptdp

Cahen, D., Keeley, L.H., Van Noten, F.L., Behm, J.A., Busby, C.I., Dunnell, R.C., Hayden, B., Johnson, L.L., Katz, P., Mohapatra, G.C., Movius, H.L., Narr, K.J., Newcomer, M., Newell, R.R., Odell, G.H., Ohel, M.Y., Paddayya, K., Pittioni, R., Roe, D.A., Tomenchuk, J., Wynn, T.G., 1979. Stone Tools, Toolkits, and Human Behavior in Prehistory [and Comments and Reply]. Current Anthropology 20, 661-683. https://doi.org/10.1086/202371

Cashmore, L., 2009. Can hominin 'handedness' be accurately assessed? Annals of Human Biology 36, 624641. https://doi.org/10/d4rmtq

Cashmore, L., Uomini, N., Chapelain, A., 2008. The evolution of handedness in humans and great apes: a review and current issues. Journal of Anthropological Sciences 86, 7-35.

Chapelain, A.S., Hogervorst, E., Mbonzo, P., Hopkins, W.D., 2011. Hand Preferences for Bimanual Coordination in 77 Bonobos (Pan paniscus): Replication and Extension. International Journal of Primatology 32, 491-510. https://doi.org/10/bt29md

Condemi, S., Monge, J., Quertelet, S., Frayer, D.W., Combier, J., 2017. Vergisson 4: a left-handed Neandertal: CONDEMI et al. Am. J. Phys. Anthropol. 162, 186-190. https://doi.org/10.1002/ajpa.23101

Corballis, M.C., 2003. From mouth to hand: Gesture, speech, and the evolution of right-handedness. Behavioral and Brain Sciences 26, 199-260. https://doi.org/10.1017/S0140525X03000062

Corballis, M.C., 1987. Straw monkeys. Behavioral and Brain Sciences 10, 269-270. https://doi.org/10/dkzpkc

Cornford, J.M., 1986. Specialized resharpening techniques and evidence of handedness, in: La Cotte de St. Brelade 1961-1978: Excavations by C.B.M. McBurney. P. Callow and J. M. Cornford, Norwich, UK, pp. 337-351 \& 413-414.

D'Errico, F., 1992. Technology, Motion, and the Meaning of Epipaleolithic Art. Current Anthropology 33, 94109. https://doi.org/10/cp4mmp

Domínguez-Rodrigo, M., Baquedano, E., 2018. Distinguishing butchery cut marks from crocodile bite marks through machine learning methods. Scientific Reports 8, 5786. https://doi.org/10.1038/s41598018-24071-1 
Estalrrich, A., Rosas, A., 2013. Handedness in Neandertals from the El Sidrón (Asturias, Spain): Evidence from Instrumental Striations with Ontogenetic Inferences. PLoS ONE 8, e62797. https://doi.org/10.1371/journal.pone.0062797

Fagot, J., Vauclair, J., 1991. Manual Laterality in Nonhuman Primates: A Distinction Between Handedness and Manual Specialization. Psychological Bulletin 109, 76-89. https://doi.org/10/fmzg86

Faurie, C., Raymond, M., Uomini, N., 2016. Origins, Development, and Persistence of Laterality in Humans, in: Laterality in Sports. Elsevier, pp. 11-30. https://doi.org/10.1016/B978-0-12-801426-4.00002-X

Faurie, C., Schiefenhövel, W., le Bomin, S., Billiard, S., Raymond, M., 2005. Variation in the Frequency of Left-handedness in Traditional Societies. Current Anthropology 46, 142-147. https://doi.org/10/c463bt

Fiore, I., Bondioli, L., Radovč, J., Frayer, D.W., 2015. Handedness in the Krapina Neandertals: A ReEvaluation. PaleoAnthropology 19-36. https://doi.org/10.4207/PA.2015.ART93

Forrester, G.S., Leavens, D.A., Quaresmini, C., Vallortigara, G., 2011. Target animacy influences gorilla handedness. Animal Cognition 14, 903-907. https://doi.org/10/c63rh6

Forrester, G.S., Quaresmini, C., Leavens, D.A., Mareschal, D., Thomas, M.S.C., 2013. Human handedness: An inherited evolutionary trait. Behavioural Brain Research 237, 200-206. https://doi.org/10/gfvwfp

Forrester, G.S., Quaresmini, C., Leavens, D.A., Spiezio, C., Vallortigara, G., 2012. Target animacy influences chimpanzee handedness. Animal Cognition 15, 1121-1127. https://doi.org/10.1007/s10071-0120536-4

Foster, A., Buckley, H., Tayles, N., 2014. Using Enthesis Robusticity to Infer Activity in the Past: A Review. Journal of Archaeological Method and Theory 21, 511-533. https://doi.org/10.1007/s10816-0129156-1

Frayer, D.W., Fiore, I., Lalueza-Fox, C., Radovčić, J., Bondioli, L., 2010. Right handed Neandertals: Vindija and beyond. Journal of Anthropological Sciences 88, 113-127.

Frayer, D.W., Lozano, M., Bermúdez de Castro, J.M., Carbonell, E., Arsuaga, J.L., Radovčić, J., Fiore, I., Bondioli, L., 2012. More than 500,000 years of right-handedness in Europe. Laterality: Asymmetries of Body, Brain and Cognition 17, 51-69. https://doi.org/10/cvjwwx

Frey, S.H., Gerry, V.E., 2006. Modulation of Neural Activity during Observational Learning of Actions and Their Sequential Orders. J. Neurosci. 26, 13194-13201. https://doi.org/10.1523/JNEUROSCI.391406.2006

Greenfield, P.M., 1991. Language, tools and brain: The ontogeny and phylogeny of hierarchically organized sequential behavior. Behavioral and Brain Sciences 14, 531-551. https://doi.org/10.1017/S0140525X00071235

Gunz, P., Mitteroecker, P., 2013. Semilandmarks: a method for quantifying curves and surfaces. Hystrix, the Italian Journal of Mammalogy 24. https://doi.org/10.4404/hystrix-24.1-6292

Hartmann, K., Goldenberg, G., Daumüller, M., Hermsdörfer, J., 2005. It takes the whole brain to make a cup of coffee: the neuropsychology of naturalistic actions involving technical devices. Neuropsychologia 43, 625-637. https://doi.org/10.1016/j.neuropsychologia.2004.07.015

Ho Ho Committee, 1979. The Ho Ho Classification and Nomenclature Committee Report, in: Lithic UseWear Analysis. Academic Press, pp. 133-135.

Holloway, R.L., 1981. Volumetric and asymmetry determinations on recent hominid endocasts: Spy I and II, Djebel Ihroud I, and the salèHomo erectus specimens, with some notes on neandertal brain size. American Journal of Physical Anthropology 55, 385-393. https://doi.org/10/dtm84g

Holloway, R.L., De La Costelareymondie, M.C., 1982. Brain endocast asymmetry in pongids and hominids: Some preliminary findings on the paleontology of cerebral dominance. American Journal of Physical Anthropology 58, 101-110. https://doi.org/10/c2dxkh

Hopkins, W.D., 2006. Comparative and familial analysis of handedness in great apes. Psychological Bulletin 132, 538-559. https://doi.org/10.1037/0033-2909.132.4.538

Hopkins, W.D., Phillips, K.A., Bania, A., Calcutt, S.E., Gardner, M., Russell, J., Schaeffer, J., Lonsdorf, E.V., Ross, S.R., Schapiro, S.J., 2011. Hand Preferences for Coordinated Bimanual Actions in 777 Great Apes: Implications for the Evolution of Handedness in Hominins. J Hum Evol 60, 605-611. https://doi.org/10/frhrc4 
lovita, R., Schönekeß, H., Gaudzinski-Windheuser, S., Jäger, F., 2014. Projectile impact fractures and launching mechanisms: results of a controlled ballistic experiment using replica Levallois points. Journal of Archaeological Science 48, 73-83. https://doi.org/10.1016/j.jas.2013.01.031

Johnson-Frey, S.H., Newman-Norlund, R., Grafton, S.T., 2005. A Distributed Left Hemisphere Network Active During Planning of Everyday Tool Use Skills. Cereb Cortex 15, 681-695. https://doi.org/10.1093/cercor/bhh169

Karakostis, F.A., Hotz, G., Scherf, H., Wahl, J., Harvati, K., 2017. Occupational manual activity is reflected on the patterns among hand entheses. American Journal of Physical Anthropology 164, 30-40. https://doi.org/10.1002/ajpa.23253

Karakostis, F.A., Hotz, G., Tourloukis, V., Harvati, K., 2018. Evidence for precision grasping in Neandertal daily activities. Science Advances 4, eaat2369. https://doi.org/10/ct9n

Karakostis, F.A., Lorenzo, C., 2016. Morphometric patterns among the 3D surface areas of human hand entheses. American Journal of Physical Anthropology 160, 694-707. https://doi.org/10.1002/ajpa.22999

Keeley, L.H., 1977. The Functions of Paleolithic Flint Tools. Scientific American 237, 108-126. https://doi.org/10/cpdqz6

Klingenberg, C.P., 2013. Visualizations in geometric morphometrics: how to read and how to make graphs showing shape changes. Hystrix It. J. Mamm. 24, 15-24. https://doi.org/10.4404/hystrix-24.1-7691

Kuhn, A., Wing, J., Weston, S., Williams, A., Keefer, C., Engelhardt, A., Cooper, T., Mayer, Z., Kenkel, B., R Core Team, Benesty, M., Lescarbeau, R., Ziem, A., Scrucca, L., Tang, Y., Candan, C., Hunt, T., 2019. caret: Classification and Regression Training. $R$ package version 6.0-84.

Lazenby, R.A., Cooper, D.M.L., Angus, S., Hallgrímsson, B., 2008. Articular constraint, handedness, and directional asymmetry in the human second metacarpal. Journal of Human Evolution 54, 875-885. https://doi.org/10.1016/j.jhevol.2007.12.001

Lewis, J.W., 2006. Cortical Networks Related to Human Use of Tools. Neuroscientist 12, 211-231. https://doi.org/10.1177/1073858406288327

Llaurens, V., Raymond, M., Faurie, C., 2009. Why are some people left-handed? An evolutionary perspective. Philosophical Transactions of the Royal Society B: Biological Sciences 364, 881-894. https://doi.org/10.1098/rstb.2008.0235

Lozano, M., Estalrrich, A., Bondioli, L., Fiore, I., Castro, J.-M.B. de, Arsuaga, J.L., Carbonell, E., Rosas, A., Frayer, D.W., 2017. Right-handed fossil humans. Evolutionary Anthropology: Issues, News, and Reviews 26, 313-324. https://doi.org/10.1002/evan.21554

Lozano, M., Mosquera, M., de Castro, J.M.B., Arsuaga, J.L., Carbonell, E., 2009. Right handedness of Homo heidelbergensis from Sima de los Huesos (Atapuerca, Spain) 500,000 years ago. Evolution and Human Behavior 30, 369-376. https://doi.org/10/b3q3mx

Marzke, M.W., 2013. Tool making, hand morphology and fossil hominins. Philosophical Transactions of the Royal Society B: Biological Sciences 368, 20120414-20120414. https://doi.org/10.1098/rstb.2012.0414

McGrew, W.C., Marchant, L.F., 1997. On the other hand: Current issues in and meta-analysis of the behavioral laterality of hand function in nonhuman primates. Yearbook of Physical Anthropology 40, 201-232.

McManus, I.C., 2009. The history and geography of human handedness, in: Sommer, I.E.C., Kahn, R.S. (Eds.), Language Lateralization and Psychosis. Cambridge University Press, Cambridge, pp. 37-58. https://doi.org/10.1017/СBO9780511576744.004

Meguerditchian, A., Vauclair, J., Hopkins, W.D., 2013. On the origins of human handedness and language: A comparative review of hand preferences for bimanual coordinated actions and gestural communication in nonhuman primates. Developmental Psychobiology 55, 637-650. https://doi.org/10/gfvtpw

Mosquera, M., Geribàs, N., Bargalló, A., Llorente, M., Riba, D., 2012. Complex Tasks Force Hand Laterality and Technological Behaviour in Naturalistically Housed Chimpanzees: Inferences in Hominin Evolution. The Scientific World Journal 2012, 1-12. https://doi.org/10/gb8dxd

Newcomer, M.H., Sieveking, G. de G., 1980. Experimental Flake Scatter-Patterns: A New Interpretative Technique. Journal of Field Archaeology 7, 345-352. 
Patterson, J.B., Sollberger, L.W., 1986. Comments on Toth's Right-Handedness Study. Lithic Technology 15, 109-111. https://doi.org/10/gfvtpx

Perez, S.I., Bernal, V., Gonzalez, P.N., 2006. Differences between sliding semi-landmark methods in geometric morphometrics, with an application to human craniofacial and dental variation. Journal of Anatomy 208, 769-784. https://doi.org/10.1111/j.1469-7580.2006.00576.x

Pobiner, B.L., 1999. The Use of Stone Tools to Determine Handedness in Hominids. Current Anthropology 40, 90-92. https://doi.org/10/c9w3md

Porac, C., Coren, S., 1981. Lateral Preferences and Human Behavior. Springer-Verlag, New York.

Pouydebat, E., Borel, A., Chotard, H., Fragaszy, D., 2014. Hand preference in fast-moving versus slowmoving actions in capuchin, Sapajus spp., and squirrel monkeys, Saimiri sciureus. Animal Behaviour 97, 113-123. https://doi.org/10/f6prdn

Poza-Rey, E.M., Lozano, M., Arsuaga, J.L., 2017. Brain asymmetries and handedness in the specimens from the Sima de los Huesos site (Atapuerca, Spain). Quaternary International 433, 32-44. https://doi.org/10.1016/j.quaint.2015.10.004

Provins, K.A., 1997. The Specificity of Motor Skill and Manual Asymmetry: A Review of the Evidence and Its Implications. Journal of Motor Behavior 29, 183-192. https://doi.org/10.1080/00222899709600832

Quaresmini, C., Forrester, G.S., Spiezio, C., Vallortigara, G., 2014. Social environment elicits lateralized behaviors in gorillas (Gorilla gorilla gorilla) and chimpanzees (Pan troglodytes). Journal of Comparative Psychology 128, 276-284. https://doi.org/10/gfvwfs

R Core Team, 2019. R: A language and environment for statistical computing. R Foundation for Statistical Computing. Vienna, Austria.

Rogers, L.J., 2009. Hand and paw preferences in relation to the lateralized brain. Philosophical Transactions of the Royal Society B: Biological Sciences 364, 943-954. https://doi.org/10/d2hdtb

Ruck, L., Broadfield, D.C., Brown, C.T., 2015. Determining hominid handedness in lithic debitage: a review of current methodologies. Lithic Technology 40, 171-188. https://doi.org/10/gfvwft

Rugg, G., Mullane, M., 2001. Inferring handedness from lithic evidence. Laterality: Asymmetries of Body, Brain and Cognition 6, 247-259. https://doi.org/10.1080/713754411

Schluter, N.D., Krams, M., Rushworth, M.F.S., Passingham, R.E., 2001. Cerebral dominance for action in the human brain: the selection of actions. Neuropsychologia 39, 105-113. https://doi.org/10.1016/S0028-3932(00)00105-6

Semenov, S.A., 1970. Prehistoric technology: an experimental study of the oldest tools and artefacts from traces of manufacture and wear. Cory, Adams \& Mackay, London.

Shaw, C.N., 2011. Is 'hand preference' coded in the hominin skeleton? An in-vivo study of bilateral morphological variation. Journal of Human Evolution 61, 480-487. https://doi.org/10/cnp7dg

Sparacello, V.S., Villotte, S., Shackelford, L.L., Trinkaus, E., 2017. Patterns of humeral asymmetry among Late Pleistocene humans. Comptes Rendus Palevol, Hominin biomechanics, virtual anatomy and inner structural morphology: From head to toe. A tribute to Laurent Puymerail 16, 680-689. https://doi.org/10/gbxm8s

Spenneman, D.R., 1984. Handedness data on the European neolithic. Neuropsychologia 22, 613-615. https://doi.org/10/bvddpn

Steele, J., Uomini, N., 2009. Can the Archaeology of Manual Specialization Tell Us Anything About Language Evolution? A Survey of the State of Play. Cambridge Archaeological Journal 19, 97. https://doi.org/10/dbjrc5

Stephens, N.B., Kivell, T.L., Gross, T., Pahr, D.H., Lazenby, R.A., Hublin, J.-J., Hershkovitz, I., Skinner, M.M., 2016. Trabecular architecture in the thumb of Pan and Homo: implications for investigating hand use, loading, and hand preference in the fossil record. American Journal of Physical Anthropology 161, 603-619. https://doi.org/10.1002/ajpa.23061

Stock, J.T., Shirley, M.K., Sarringhaus, L.A., Davies, T.G., Shaw, C.N., 2013. Skeletal evidence for variable patterns of handedness in chimpanzees, human hunter-gatherers, and recent British populations. Annals of the New York Academy of Sciences 1288, 86-99. https://doi.org/10.1111/nyas.12067

Stout, D., Chaminade, T., 2012. Stone tools, language and the brain in human evolution. Philos Trans R Soc Lond B Biol Sci 367, 75-87. https://doi.org/10.1098/rstb.2011.0099 
Stout, D., Toth, N., Schick, K., Chaminade, T., 2008. Neural correlates of Early Stone Age toolmaking: technology, language and cognition in human evolution. Philosophical Transactions of the Royal Society B: Biological Sciences 363, 1939-1949. https://doi.org/10/fk2djc

Stout, D., Toth, N., Schick, K., Stout, J., Hutchins, G., 2000. Stone Tool-Making and Brain Activation: Position Emission Tomography (PET) Studies. Journal of Archaeological Science 27, 1215-1223. https://doi.org/10/ds4vjg

Toth, N., 1985. Archaeological evidence for preferential right-handedness in the lower and middle pleistocene, and its possible implications. Journal of Human Evolution 14, 607-614. https://doi.org/10/fj9wb7

Trinkaus, E., Churchill, S.E., Ruff, C.B., 1994. Postcranial robusticity in Homo. II: Humeral bilateral asymmetry and bone plasticity. American Journal of Physical Anthropology 93, 1-34. https://doi.org/10/b8q2ws

Uomini, N., Gowlett, J., 2013. La latéralité manuelle préhistorique, les outils et le langage. Revue de primatologie 1-19. https://doi.org/10/gfvwfv

Uomini, N.T., 2011. Handedness in Neanderthals, in: Conard, N.J., Richter, J. (Eds.), Neanderthal Lifeways, Subsistence and Technology. Springer Netherlands, Dordrecht, pp. 139-154. https://doi.org/10.1007/978-94-007-0415-2_14

Uomini, N.T., 2009. The prehistory of handedness: Archaeological data and comparative ethology. Journal of Human Evolution 57, 411-419. https://doi.org/10.1016/j.jhevol.2009.02.012

Uomini, N.T., 2008. In the knapper's hands: identifying handedness from lithic production and use, in: Prehistoric Technology. 40 Years Later: Functional Studies and the Russian Legacy, BAR International Series. pp. 51-62.

Uomini, N.T., 2001. Lithic indicators of handedness: assessment of methodologies and the evolution of laterality in hominids (M.Sc. Dissertation). University of Durham, Durham.

Uomini, N.T., Meyer, G.F., 2013. Shared Brain Lateralization Patterns in Language and Acheulean Stone Tool Production: A Functional Transcranial Doppler Ultrasound Study. PLoS ONE 8, e72693. https://doi.org/10.1371/journal.pone.0072693

Vallortigara, G., Rogers, L.J., 2005. survival with an asymmetrical brain: advantages and disadvantages of cerebral lateralization. Behavioral and Brain Sciences 28, 575-589. https://doi.org/10.1017/S0140525X05000105

Weber, T., 1990. Analysen der archäologischen Funde und des Befunds, in: Neumark-Gröbern: Beiträge Zur Jagd Des Mittelpaläolithischen Menschen, Veröffentlichungen Des Landesmuseums Für Vorgeschichte in Halle. D. Mania, M. Thomae, T. Litt and T. Weber, Berlin, pp. 237-255.

Willems, R.M., Hagoort, P., 2007. Neural evidence for the interplay between language, gesture, and action: A review. Brain and Language, Gesture, Brain, and Language 101, 278-289. https://doi.org/10.1016/j.bandl.2007.03.004

Xing, S., O'Hara, M., Guatelli-Steinberg, D., Ge, J., Liu, W., 2017. Dental Scratches and Handedness in East Asian Early Pleistocene Hominins: Handedness of East Asian Hominin. Int. J. Osteoarchaeol. 27, 937-946. https://doi.org/10.1002/oa.2601 
Fig.1: Soda-lime glass replica used in the experiment.

Fig.2: Documentation of the type, orientation and position of maximum extent of the micro-scars.

Fig.3: Used edges curves extraction for geometric morphometric analysis. A) Example of photograph taken after use. B) Binarization. C) Scaling of outlines. D) The line going through the extremities of each outline is placed horizontally, the outlines are then wedged on the rightmost point. E) The average coordinates of the uppermost points of the outlines is calculated and the uppermost point of each outline is aligned on it. F) The edge of interest is extracted by cutting the outline at the uppermost point and at the leftmost point.

Fig.4: Examples of position and orientation of micro-scars for left and right-handers.

Fig.5: Comparison of tool edges before and after use for left and right-handers.

Fig.6: Two first axes of the principal component analysis of the coordinates obtained by Generalized Procrustean Analysis (GPA) of the curves representing the used edges of the tools used by left-handers and right-handers. The used edge shape reconstructions are displayed for the minimum and the maximum values of each PC.

Table 1: Results of the $\mathrm{k}$ Nearest Neighbours models. Models providing the best accuracy are in bold. 



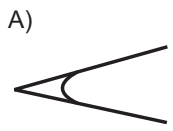

Break

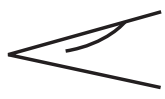

Feathered

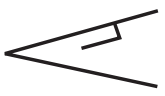

Step

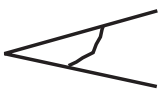

Abrupt

\section{After Vaughan (1985)}

B)

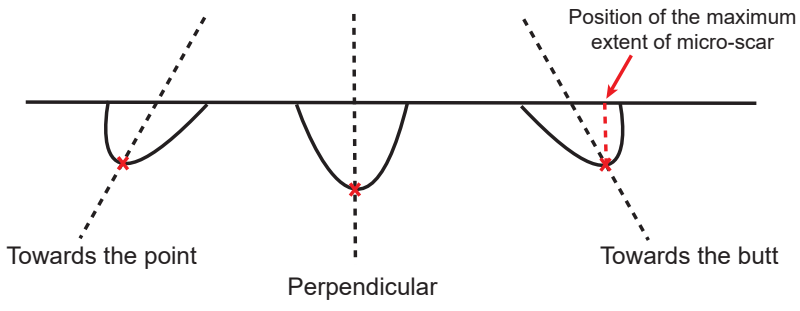

. . . . . : : Micro-scar axis

x : Maximum extent of micro-scar

: Micro-scar 


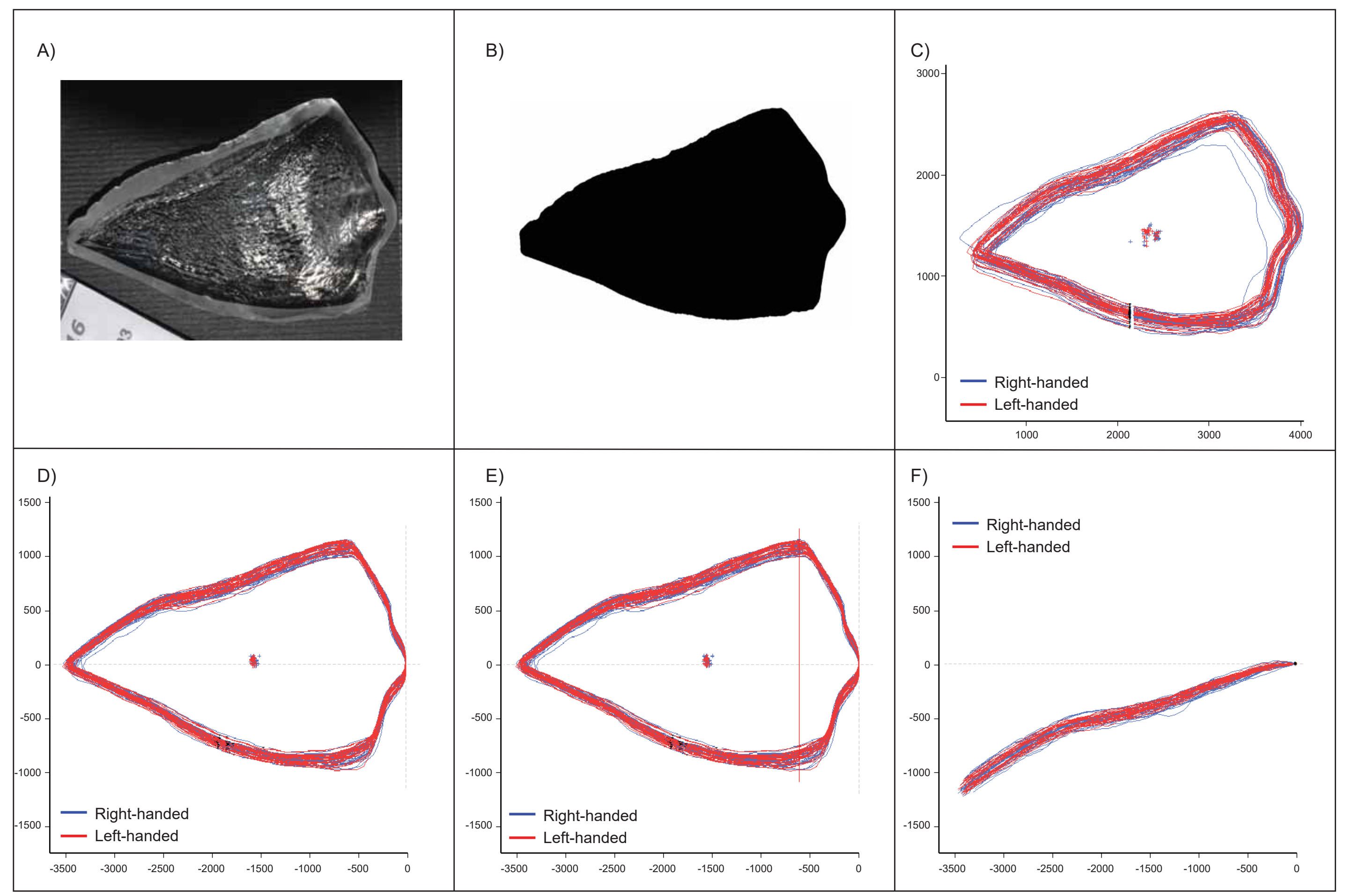


Tool used by a left-hander
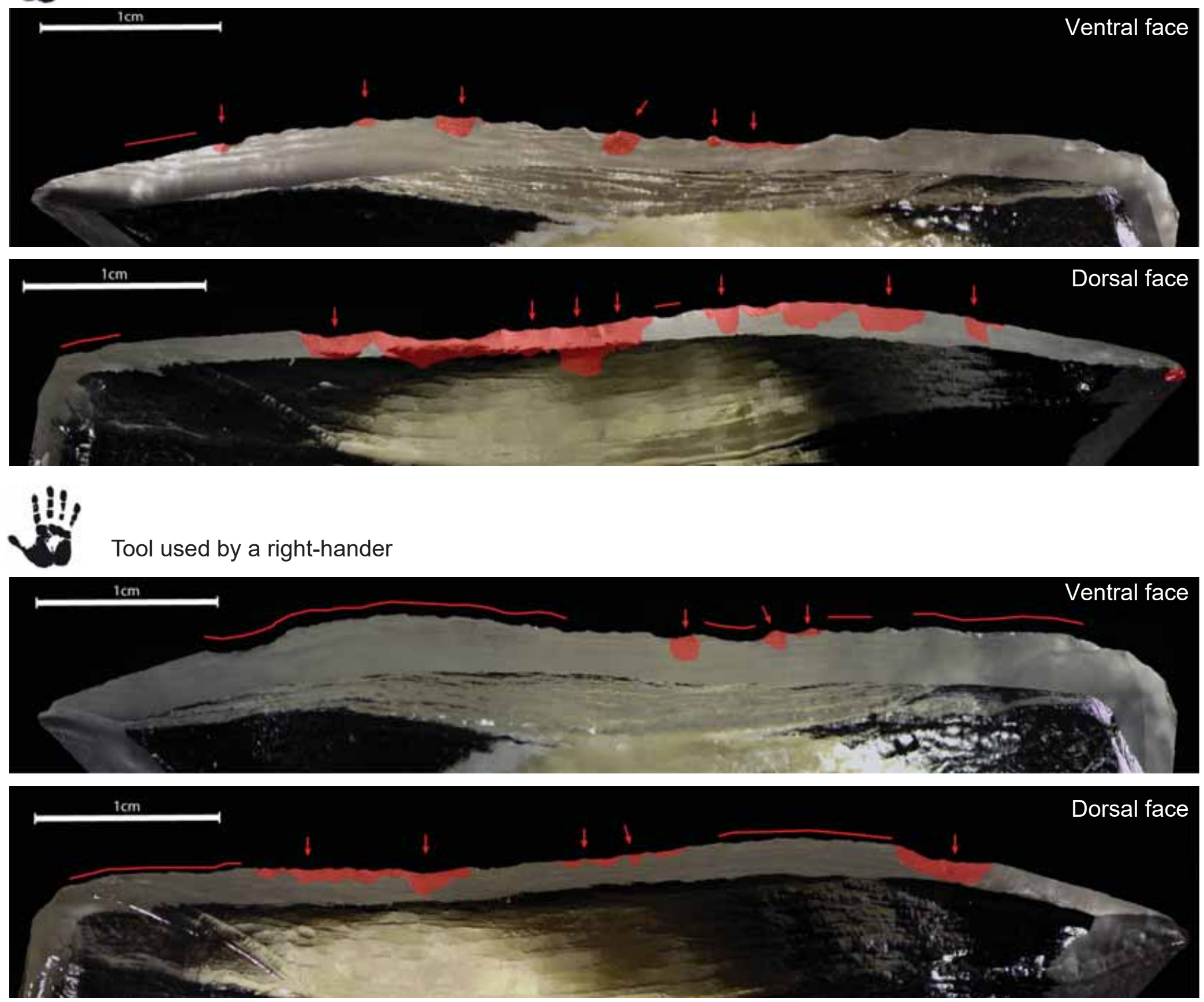

$\downarrow$ : General orientation of the micro-scars $\quad$ : Micro-scars extent

: Edge modification visible at a magnification higher than $10 \mathrm{X}$ 


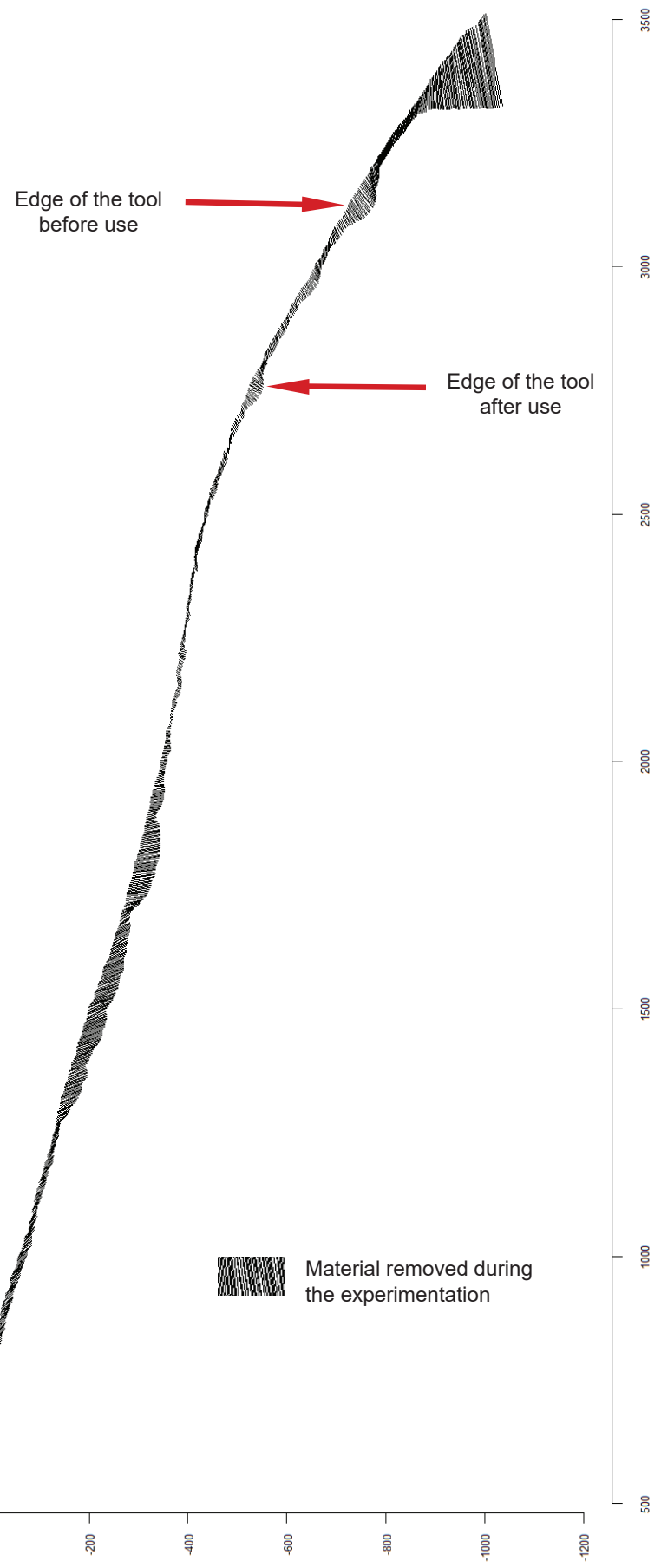




\begin{tabular}{|c|c|c|c|c|c|c|c|}
\hline 1 & Number of scars on the ventral and dorsal faces of the tool & 23 & 0.65 & $0.5160,0.7687$ & 0.3092 & 0.7407 & 0.5758 \\
\hline 2 & Types of scars on both faces & $9 \& 11$ & 0.6833 & $0.5504,0.7974$ & 0.3537 & 0.5926 & 0.7576 \\
\hline 3 & Types of scars on dorsal face & 5 & 0.7 & $0.5679,0.8115$ & 0.398 & 0.7037 & 0.6970 \\
\hline 4 & Types of scars on ventral face & 31 & 0.6 & $0.4654,0.7244$ & 0.1864 & 0.5185 & 0.6667 \\
\hline 5 & Directions of scars on both faces & $17 \& 27$ & 0.6 & $0.4654,0.7244$ & 0.2131 & 0.7037 & 0.5152 \\
\hline 6 & Directions of scars on dorsal face & 41 & 0.6333 & $0.499,0.7541$ & 0.2834 & 0.7778 & 0.5152 \\
\hline 7 & Directions of scars on ventral face & 21 & 0.6333 & $0.499,0.7541$ & 0.2691 & 0.6667 & 0.6061 \\
\hline 8 & Types and directions of scars on both faces & 25 & 0.65 & $0.516,0.7687$ & 0.3 & 0.6667 & 0.6364 \\
\hline 9 & Number, types and directions of scars on both faces & 27 & 0.6167 & $0.4821,0.7393$ & 0.2333 & 0.6296 & 0.6061 \\
\hline 10 & $\begin{array}{l}\text { The } 59 \text { first principal components of the PCA on geometric } \\
\text { morphometrics data }\end{array}$ & $55 \& 57 \& 59$ & 0.55 & $0.4161,0.6788$ & 0 & 0 & 1 \\
\hline 11 & $\begin{array}{l}\text { The } 2 \text { first principal components of the PCA on geometric } \\
\text { morphometrics data }\end{array}$ & 31 & 0.5833 & $0.4488,0.7093$ & 0.1776 & 0.6667 & 0.5152 \\
\hline 12 & $\begin{array}{l}\text { The } 59 \text { first principal components of the PCA on geometric } \\
\text { morphometrics data and the number of scars on both faces }\end{array}$ & $13 \& 15$ & 0.65 & $0.516,0.7687$ & 0.3 & 0.6667 & 0.6364 \\
\hline 13 & $\begin{array}{l}\text { Position of the scar with the maximum extent on the surface } \\
\text { perpendicularly to the edge on ventral face }\end{array}$ & $17 \& 47$ & 0.7333 & $0.6034,0.8393$ & 0.4539 & 0.6296 & 0.8182 \\
\hline 14 & $\begin{array}{l}\text { Position of the scar with the maximum extent on the surface } \\
\text { perpendicularly to the edge on dorsal face }\end{array}$ & $21 \& 23$ & 0.5833 & $0.4488,0.7093$ & 0.1611 & 0.5556 & 0.6061 \\
\hline 15 & $\begin{array}{l}\text { Position of the scar with the maximum extent on the surface } \\
\text { perpendicularly to the edge on both faces }\end{array}$ & 11 & 0.7333 & $0.6034,0.8393$ & 0.4613 & 0.7037 & 0.7576 \\
\hline 16 & $\begin{array}{l}\text { Maximum scar extent on the surface perpendicularly to the } \\
\text { edge on ventral face }\end{array}$ & $25 \& 37$ & 0.75 & $0.6214,0.8528$ & 0.4966 & 0.7407 & 0.7576 \\
\hline 17 & $\begin{array}{l}\text { Maximum scar extent on the surface perpendicularly to the } \\
\text { edge on dorsal face }\end{array}$ & $21 \& 23$ & 0.7333 & $0.6034,0.8393$ & 0.4613 & 0.7037 & 0.7576 \\
\hline 18 & $\begin{array}{l}\text { Maximum scar extent on the surface perpendicularly to the } \\
\text { edge on both faces }\end{array}$ & 23 & 0.75 & $0.6214,0.8528$ & 0.5 & 0.7778 & 0.7273 \\
\hline 19 & $\begin{array}{l}\text { Maximum scar extent and position of the scar with the } \\
\text { maximum extent on the surface perpendicularly to the edge on } \\
\text { both faces }\end{array}$ & 5 & 0.75 & $0.6214,0.8528$ & 0.5066 & 0.8519 & 0.6667 \\
\hline 20 & All descriptors from microscopic observation & 5 & 0.75 & $0.6214,0.8528$ & 0.5 & 0.7778 & 0.7273 \\
\hline 21 & $\begin{array}{l}\text { All descriptors from microscopic observation and geometric } \\
\text { morphometrics }\end{array}$ & 9 & 0.75 & $0.6214,0.8528$ & 0.5066 & 0.8519 & 0.6667 \\
\hline
\end{tabular}

